\title{
Simulation of wheel heating when drum braking
}

\author{
Aleksander Mironov ${ }^{1}$, Pavel Shalupina, ${ }^{2, *}$, Aleksander Pavlyukov², and Ivan Dobychin ${ }^{2}$ \\ "'Infoteks AT" LLC, 620017 Yekaterinburg, Russia \\ ${ }^{2}$ Ural State University of Railway Transport, 620034 Yekaterinburg, Russia
}

\begin{abstract}
Application of heating control systems is rational for effective prevention of thermal-mechanical damages of the wheels and brake shoes of rolling stock. These systems enable to perform diagnosis of brake equipment elements and to evaluate the effectiveness of drum braking process in terms of wheel heating. The present study aims to assess wheel heating when drum braking and to define the most informative zones and threshold control values for heating control systems. Heating evaluation is conducted using finite element method under different braking modes. Research results are given as heating patterns in solid-rolled wheel of freight car; the influence of the air distributor mode on the wheel heating is considered, the most informative zones for heating control are identified.
\end{abstract}

\section{Introduction}

Heating control systems (HCS) are effective means to detect pre-failure conditions of brake equipment and prevent thermal-mechanical damages of brake system elements. They are widely used at the railroads of Russia and in European Union countries [1], the USA [2], Canada [3], and India due to operating principle of rolling stock brake system. Friction brakes are applied on rolling stock to control the travel velocity; their basic operating principle lies in conversion of the mechanical energy of motion into thermal energy due to friction. Multiple freight cars apply drum brakes, where brake shoes press against wheel thread to decelerate the motion of the vehicle.

Starting from the 1960s, brake shoes made from polymer composites became commonly used at the railroads. Compared to cast-iron brake shoes, composite shoes possess lower weight, more consistent friction coefficient at the whole velocity range and high operational life. However they differ by a number of significant drawbacks. The first experience of using brake shoes made from $6 \mathrm{KV}-10$ composite showed that the average number of wheel pairs with surface damages increased by 10 times. For the first time in maintenance the problem appeared when wheel wear products were carried over the adjacent surfaces of brake shoes made from polymer composites [4]. Due to that the braking process was accompanied by excessive wear and occurrence of defects of thermalmechanical nature. Despite ongoing enhancement of the polymer composition for brake shoes, their basic problem still remains which is the low value of thermal conductivity and therefore increased thermal load on the wheels. Studies have shown that $95-97 \%$ of heat

${ }^{*}$ Corresponding author: p.shalupina@gmail.com 
generated during braking is dissipated by wheels; while brake shoes from polymer composites dissipate only $3-5 \%$ of heat (cast-iron brake shoes dissipate over 10-15\%) [5].

Low thermal conductivity of polymer composites and increased thermal load on the wheels along with the common failures taking place when working with automatic brakes of rolling stock to a large extent increase the damage rate of the wheels and brake shoes. The cases of automatic braking equipment failure in Russian railroads amount to $39 \%$ out of the total number of failures, in absolute numbers it is 3809 cases of failure in 2017. Such high value is also conditioned by a significant number of thermal-mechanical damages of the wheels, such as voids, wheel flats, weld-on deposits and circumferential wear [6].

HCS allow performing diagnosis of braking equipment elements and evaluate the effectiveness of braking process by heating of friction surfaces. Their working principle is based on the emission phenomenon - any body having the temperature higher than the absolute zero $\left(-273.15^{\circ} \mathrm{C}\right)$ emits electromagnetic waves. The intensity and wave length depends on the body temperature according to Planck's equation and Wien's law [7]. A challenging issue while developing HCS is defining accurate and proper information and the heating degree of braking system elements. Whereas the ultimate purpose of HCS application is reduction of operating expenses of railroads, defining proper threshold values and control zones on the braking system elements is a primary objective.

Therefore the present study aims to deliver information in the field of threshold values and thermal control zones of wheels in freight car to develop HCS. The first stage of this objective is appropriate to be solved by means of simulation modeling. The heating process of solid-rolled wheels of freight car during braking by composite brake shoe was investigated in the present paper by finite element analysis. The essential difference of this study from the previously conducted ones $[2,8,9]$ consists in the development of full-scale model corresponding to the real wheel structure and brake shoe. Such approach enables to clarify the pattern and degree of wheel heating during different braking modes.

\section{Materials and methods}

The heating process during braking was investigated on the example of solid-rolled wheel and brake shoe from polymer composite. The model of solid-rolled wheel corresponds to Russian National State Standard GOST 10791-2011 with the tread diameter of $950 \mathrm{~mm}$. Based on solid models of freight car wheel, and brake shoe made from polymer composite (Fig. 1) their finite element models were developed using solid finite elements of hexahedral and tetrahedral shapes.

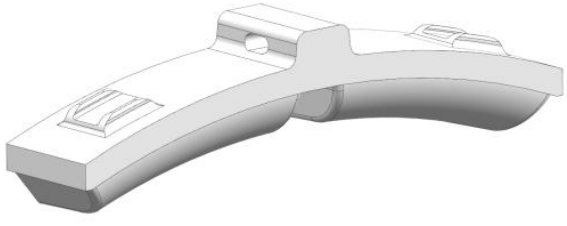

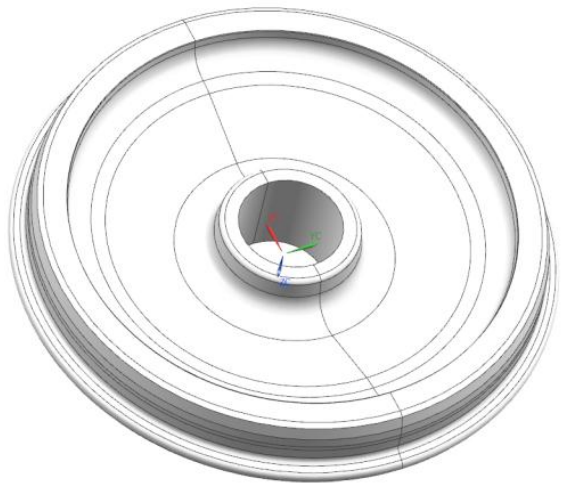

b

Fig. 1. Solid models of wheel and brake shoes: a - solid model of brake shoe made from polymer composite, $\mathrm{b}$ - solid model of wheel. 
Part of the finite element model is shown in Figure 2 as an example.

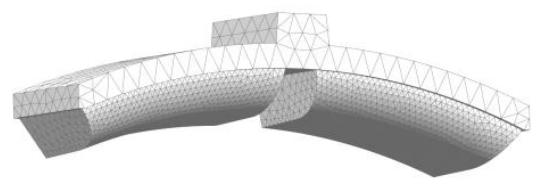

a

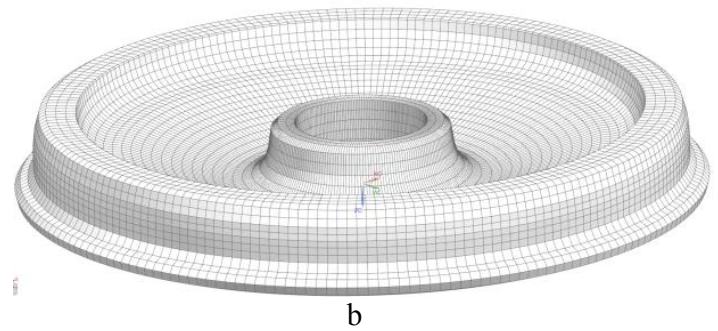

Fig. 2. Finite element model: a - Finite element model of brake shoe from polymer composite (number of nodes - 3,036), b- Finite element model of the wheel (number of nodes -42,224).

The developed model takes into account the number of parameters given in Table 1.

Table 1. Parameters considered in simulation.

\begin{tabular}{|c|c|c|c|c|c|}
\hline Simulation specification & Notation & Dimensions & \multicolumn{3}{|c|}{ Numeric value } \\
\hline \multirow{7}{*}{$\begin{array}{l}\text { 1. Materials properties: } \\
\text { - density } \\
\text { - Young's modulus } \\
\text { - Poisson's ratio } \\
\text { - thermal capacity } \\
\text { - heat transfer coefficient } \\
\text { - linear expansion coefficient }\end{array}$} & \multirow{6}{*}{$\rho$} & \multirow{6}{*}{$\begin{array}{c}\mathrm{kg} / \mathrm{m}^{3} \\
\mathrm{~Pa} \\
- \\
\mathrm{J} / \mathrm{kg} \cdot \mathrm{K} \\
\mathrm{W} / \mathrm{m} \cdot \mathrm{K}\end{array}$} & \multicolumn{2}{|c|}{$\begin{array}{l}\text { Solid-rolled } \\
\text { wheel }\end{array}$} & $\begin{array}{c}\text { Brake } \\
\text { shoe }\end{array}$ \\
\hline & & & \multicolumn{2}{|c|}{$\begin{array}{c}7850 \\
2.1 \cdot 10^{11}\end{array}$} & $\begin{array}{c}2100 \\
10 \cdot 10^{11}\end{array}$ \\
\hline & & & \multicolumn{2}{|c|}{0.28} & 0.3 \\
\hline & & & \multicolumn{2}{|c|}{486} & 430 \\
\hline & & & \multicolumn{2}{|c|}{7920} & - \\
\hline & & & \multirow{2}{*}{\multicolumn{2}{|c|}{11.6}} & 30 \\
\hline & $\alpha$ & $10^{-6} \cdot \mathrm{K}^{-1}$ & & & \\
\hline \multirow[b]{3}{*}{$\begin{array}{l}\text { 2. Compressive force acting } \\
\text { on brake shoe: }\end{array}$} & \multirow[b]{3}{*}{$F_{N}$} & \multirow[b]{3}{*}{ tf } & \multicolumn{3}{|c|}{ Air distributor mode } \\
\hline & & & Empty & Average & Loaded \\
\hline & & & 0.82 & 1.48 & 2.4 \\
\hline 3. Ambient temparature & $T_{a m b}$ & ${ }^{\circ} \mathrm{C}$ & \multicolumn{3}{|c|}{20} \\
\hline 4. Axial load & $q_{0}$ & $\mathrm{kN}$ & \multicolumn{3}{|c|}{245} \\
\hline
\end{tabular}

Contact area between solid-rolled wheels and brake shoe from polymer composite is about $0.29 \mathrm{~m}^{2}$. The change in friction coefficient in the contact between solid-rolled wheel and brake shoe is taken into account depending on motion velocity according to the known empirical dependencies.

During drum braking heat flow goes into the wheel through the wheel tread contacting with the brake shoe. It is changed in a complex manner and it depends on the specific braking force $b(t)$ at each moment of time $t$, velocity of train car $\vartheta(t)$, axial load of train car $q_{o}$ and friction surface of brake shoe $A[8,9]$ :

$$
q(t)=\frac{b(t) \vartheta(t) q_{o}}{A}
$$

Mathematical model applied to define the heat flow density, suggests that heat flow $q(t)$ grows nonlinearly from zero to maximum when brake cylinders are filled with compressed air. Since the pressure in brake cylinder is increased up to a maximum point the train velocity and heat emission decrease up to zero. Mathematical model takes into account the 
fact that during braking the heat flow $q_{I}(t)$ is directed into brake shoe, while the heat flow $q_{2}(t)$ - into the wheel rim. Part of heat given as heat flow $q_{3}(t)$ is released into the environment. The value of each heat flow is defined according to the following dependencies:

$$
\begin{gathered}
q_{1}(t)=\alpha \cdot q(t), \\
q_{2}(t)=(1-\alpha) \cdot q(t), \\
q_{3}(t)=\alpha^{\prime}(t)\left[T_{2}(0, t)-T_{c}\right],
\end{gathered}
$$

where $\alpha$ - part of the heat flow directed into the brake shoe (heat flow sharing coefficient), for composite brake shoe $\alpha=0.05 ; \alpha^{\prime}(t)$ - heat exchange coefficient, $\mathrm{W} / \mathrm{m}^{3} \cdot \circ^{\circ} T_{2}(0, t)-$ temperature of wheel tread in the moment of time $t,{ }^{\circ} \mathrm{C} ; T_{c}$ - ambient temperature, ${ }^{\circ} \mathrm{C}$.

\section{Results}

In order to evaluate heating of solid-rolled wheel and brake shoe during braking design modes were formed. They consider earlier defined simulation parameters and mathematical model of defining heat flow density (Table 2). For each of the operating modes of air distributor and the type of applied brake shoe the assessment of wheel heating is conducted while braking with different initial velocities and duration.

Table 2. Design modes to evaluate wheel and brake shoe heating.

\begin{tabular}{|l|l|l|}
\hline Modes & Velocity of forward movement of rail car, $\mathrm{km} / \mathrm{h}$ & Braking time, $\mathrm{s}$ \\
\hline I & $120 \ldots 0$ & 60 \\
\hline II & $100 \ldots 0$ & 300 \\
\hline III & 15 & 1200 \\
\hline
\end{tabular}

Modes I and III are regulated by "Rules..." [10]. For each of the accepted design modes eigenvalues of heat flow density are calculated in each of the moments of time $t$. Figure 3 indicates simulation results given as heating patterns for short-term I mode and III mode, corresponding to the situation of maintaining constant velocity at the long down grade.

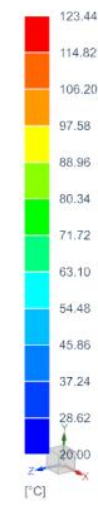

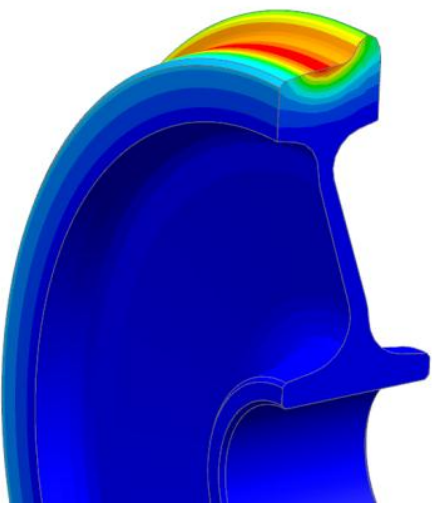

a

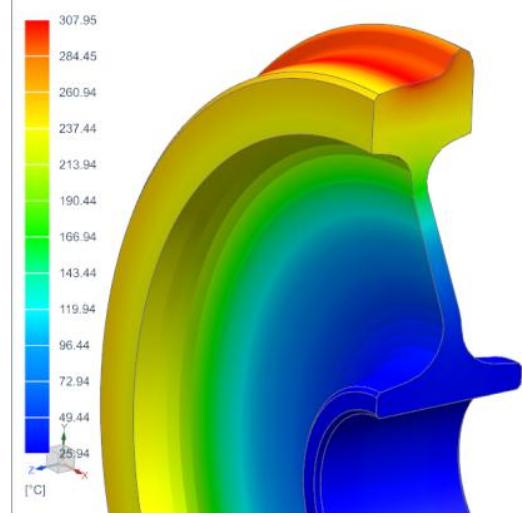

b 


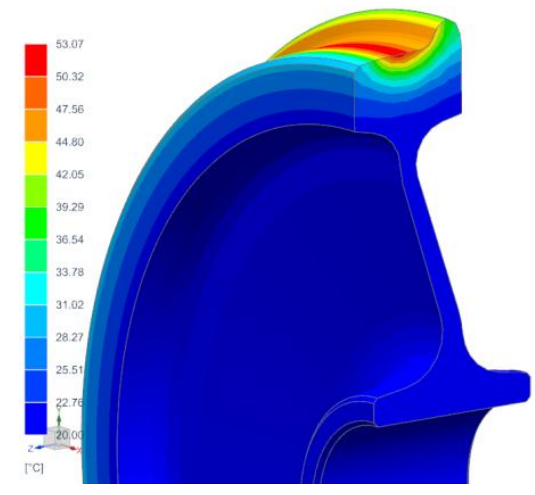

c

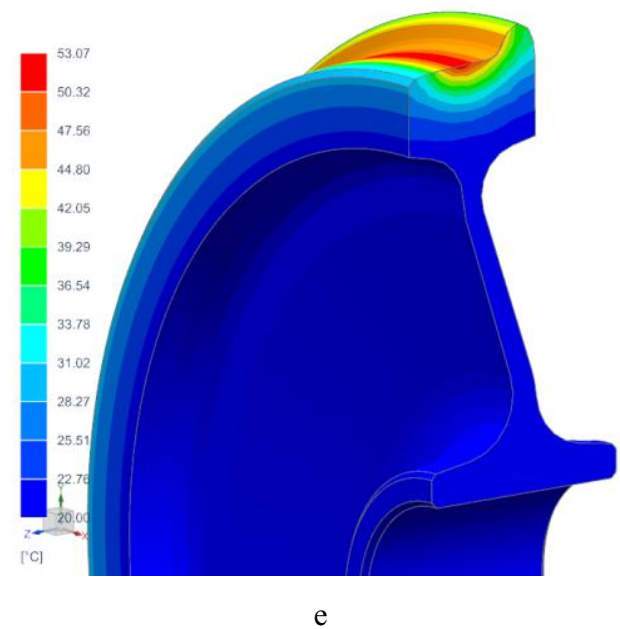

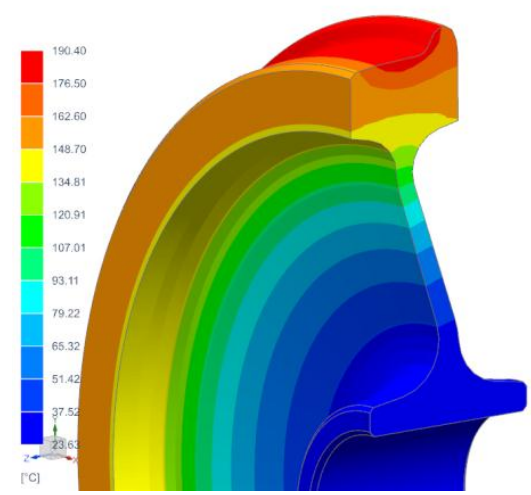

d

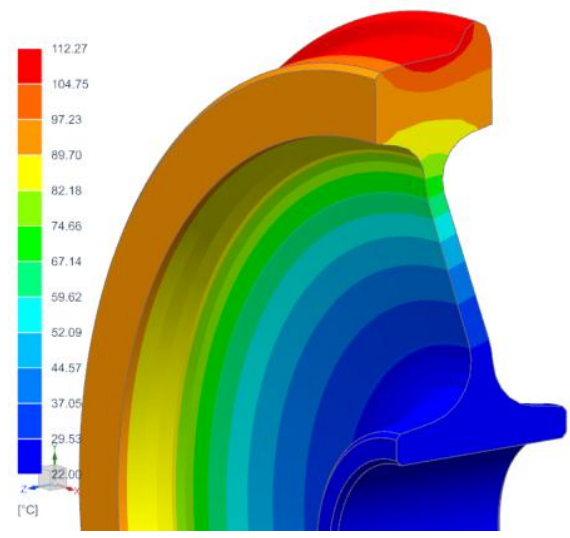

f

Fig. 3. Heating patterns by different braking modes (loaded mode of air distributor): a - mode I (loaded), b - mode III (loaded), c - mode I (average), d - mode III (average), e - mode I (empty), f mode III (empty).

Simulation results show that during short-term braking heating occurs mainly in the wheel rim. The temperature of disc part of the wheel (in the junction of the rim and the disc) changes insignificantly and it is about $25-30^{\circ} \mathrm{C}$ (mode I). The temperature of the hub during short-term braking scarcely changes. In case of long-term braking more homogenous heating of the wheel with significant growth of the rim temperature up to $305^{\circ} \mathrm{C}$ is observed when using composite brake shoes. The obtained results correlate well with the known studies [11, 12]. It is obvious that the most informative thermal control zone for HCS application is the zone of wheel profile. In that case it is rational to orient IR optics of HCS on the surface of the wheel rim from the internal or external side. It is necessary to consider the lowering of the rim height due to the wheel wear while operation.

Therefore, solving the task of selection of IR-optics orientation to control wheels has two options: orientation of IR-optics into the point lying at the contact line of the wheel and the rail or in the point located above the rim on the disc. The first option provides control of the zone which describes heating of the wheel most informatively. Such orientation enables to separate heating of the solid-rolled wheel during short-term braking. However, at the same time possibility of getting alarm signal from HCS appears in case of using emergency 
braking, as in this zone it is possible to reach the threshold control values during emergency braking. The second option with IR-optics orientation into higher point on the disc enables to define effectively the wheel overheating, as in this zone intensive temperature growth will occur. At the same time due to relatively slow heating such orientation will allow avoiding alarm signals from HCS in case of short-term or emergency braking.

\section{Conclusion}

The study on assessment of wheel heating when drum braking was conducted by means of finite element analysis. The developed full-scale models of solid-rolled wheels and brake shoe enabled to define the working temperatures of solid-rolled wheels for different braking modes with high accuracy. Full-scale heating patterns obtained from simulation allowed preliminary indicating the most informative zones of heating control on the wheel. Results of this investigation may become the basis for designing new HCS and enhancing the existing ones. The next stage in elaborating information support for HCS is conducting experimental study to evaluate heating of the wheels of train cars in operation, as well as validation of the model to evaluate wheel heating when braking developed in this study.

\section{References}

1. E. Eisenbrand, Rail Technology Review Special: Wayside Train Monitoring Systems, 2-11, (2011).

2. J. Roberda, D. Sammon, B. Madrill, Using Wheel Temperature Detector Technology to Monitor Railcar Brake System Effectiveness (Washington, U.S. Department of Transportation, 2013).

3. WWW-BST-TSB-GC-CA, Railway Investigation Report R99T0031, available at: http://www.bst-tsb.gc.ca/eng/rapports-reports/rail/1999/r99t0031/r99t0031.pdf (May 1, 2018).

4. A.Ye. Pavlyukov, O.V. Cherepov, P.I. Shalupina, Herald of the Ural State University of Railway Transport, 4, 4-11 (2017). (in Russian)

5. S.M. Zakharov, Kontaktno-ustalostnye povrezhdenija koles gruzovyh vagonov [Contact fatigue damage of the freight wagon wheels] (Intekst, Moscow, 2004). (in Russian)

6. Regional Center of Innovation Technologies, Klassifikator neispravnostej vagonnyh kolesnyh par i ih elementov [Defects classification of wagon wheel pairs and their elements, available at: http://www.rcit.su/techinfo51.html (May 1, 2018). (in Russian)

7. L.Z. Kriksunov, Spravochnik po osnovam infrakrasnoj tehniki [Handbook of the basics of infrared technology] (Sovtskoe radio, Moscow, 1978). (in Russian)

8. E.Ye. Galay, Abstract of a thesis of Candidate of sciences (Gomel, 2018). (in Russian)

9. A.V. Savrukhin, A.N. Neklyudov, R.A. Efimov, Mir transporta [World of transport and transportation], 5, 22-37 (2014). (in Russian)

10. Normy dlja rascheta i proektirovanija vagonov zheleznyh dorog MPS kolei $1520 \mathrm{~mm}$ (nesamohodnyh) [Norms for the calculation and design of railroad cars of the Ministry of Railways with gauge $1520 \mathrm{~mm}$ (non-self-propelled)] (Ministry of Railways, Moscow, 1996). (in Russian)

11. A.A. Mironov, V.L. Obraztsov, A.Ye. Pavlyukov, Transport of the Urals, 4, 24-29 (2008).

12. K. Mitura, R. Faja, Železn. techn. 3, 175-184 (1980). 